\title{
Study on the reliability of coal and gas outburst
}

\section{prevention system at mining working face}

\author{
Liping Xiao ${ }^{1}$, Xionggang $\mathrm{Xie}^{2}$ \\ 1.Guizhou Institution of Technology, Mining Engineering College, Guizhou Guiyang 550002; \\ 2.Guizhou University, Mining College, Guizhou, Guiyang 550025
}

Keywords: coal and gas outburst, monitoring, outburst prevention system, reliability

Abstract: Most of coal and gas outburst accidents in China are caused directly by human misconduct in specific circumstances, lose efficacy of gas monitoring system and storage condition changes of the coal bed. In this paper, investigation was done on each component reliability of the Man-Machine-Environment(MME) interaction system, digging device and the situation of the coal bed with its working surface. The investigation is based on the theory and method of the safety system engineering, and regard factors that may cause the outburst in the outburst prevention system. In order to devise coal and gas outburst prevention system with sufficient evidence, reliability calculation of each unit of the outburst prevention system on the working surface has been done, and the distribution and features of the reliability are analyzed based on a real case of the Wansan coal mine, Lianyuan town, Hunan province.

\section{Introduction}

The phenomenon of coal and gas outburst is a very complicated energetic failure process and in China,this kind of disaster is well known for its high frequency and high number of casualties occurred in coal mine accidents. The number of outburst wells in China is about $25 \%$ of that all around the world which makes China the most serious country on the earth for coal and gas outburst ${ }^{[1]}$. With the increase of mining depth and complexity of geology conditions, the possibility of energetic failure will also increase obviously.

In recent several decades,people having accumulated more and more knowledge about the coal and gas outburst ${ }^{[2]}$, and new method such as using combination systems ${ }^{[3]}$ of Forecasting and prediction--Prevention method against outburst- -Results verifying and security protection is an effective way and it does work for the prevention of coal and gas outburst.In safe production systems underground, it takes up 70\%-90\% which lead to systems lose effectiveness because of man's fault ${ }^{[4]}$.Most of the outburst happened under the condition of misoperation ${ }^{[2]}$, failure of gas monitoring systems and coal seams(great changes had happened on important parameters such as coal seam dip angle,the occurrence of roof and floor etc.).In this study we use the theory and method of safety system engineering,considering the system characteristic of Man-Machinery-Environments(MME) to study the features and distributions of reliability for coal seams, working environment and workers. We may prevent outburst accidents through enhancing the reliability of the outburst prevention system at the mining working face.

\section{Mine outburst prevention system}

By studying the accident cases of the coal and gas outburst in China,we know that main 
reasons which arouse the outburst may as follows: there is soft stratification between coal seams, high gas pressure gradient,gas sealed well in roof and floor,great changes in coal dip angle,the geological structure (folds, faults and fracture zones), coal seam gas distribution, coal seam thickness variation (bifurcation and consolidated Coal Mining Engineering), layout unreasonable cause stress concentration, the poor quality supporting (roof and top air operations), using hand picks picks and illegal blasting, etc.According to the theory and method of safety system engineering $^{[5]}$,the system includes three parts such as mining workers, administrators and technical persons, the material conditions of coal seam mining equipment,production and operation environment of working face.

The Man-Machinery- Environment (MME) system is shown as follows in Fig.1.

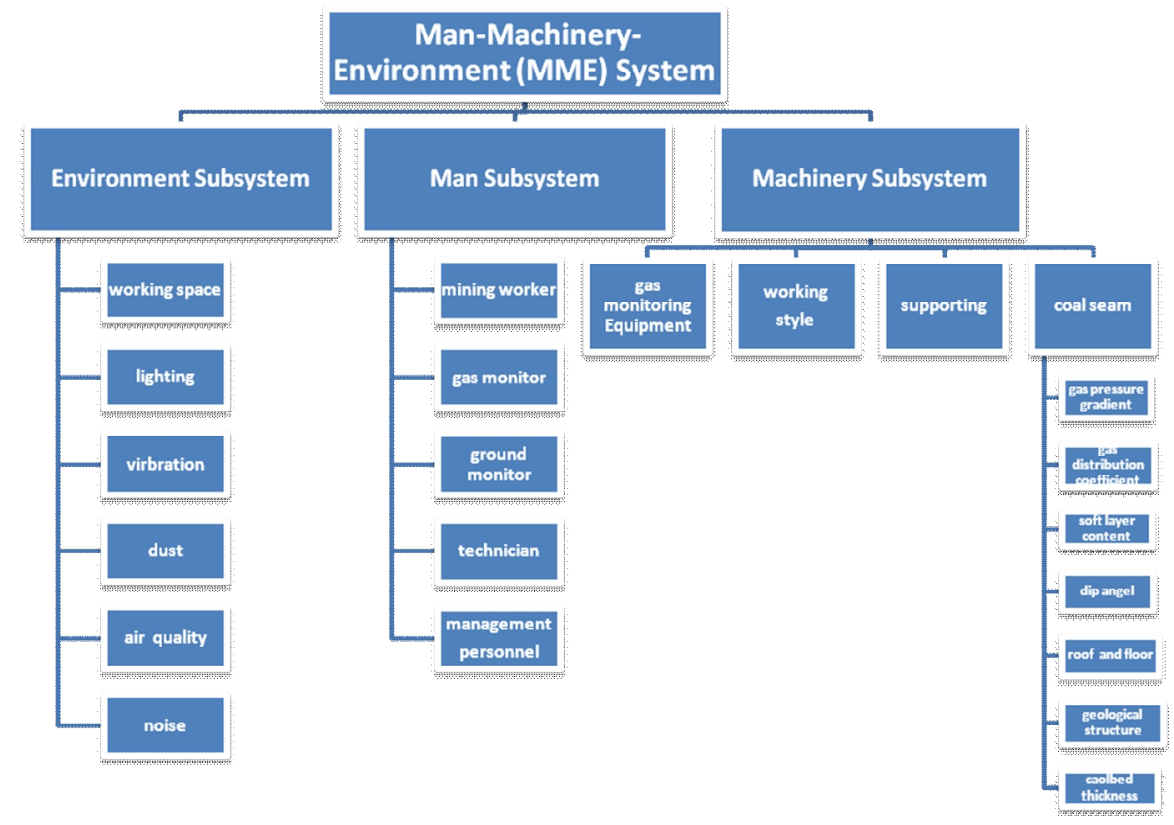

Fig.1 The Man-Machinery-Environment (MME) system

\section{System reliability}

Reliability is represented normally by the reliability and failure rate. The system reliability means the probability which completed by the system in the specified operating conditions and the prescribed period of time.In general, the reliability of the system can be expressed as $R(t)$ and there is the region $0 \ll R(t) 《 1$. The system is a synthesis which able to complete the required functions, and it is composed of by components and subsystem etc.. The reliability of the system is not only depends on the composition of the system unit, but also depends on the mutual coordination unit.

The coal seam,support, and work way can be looked as the generalized repairable unit in the outburst prevention system and the failure rate and repair rate were $\lambda_{t}$ and $\mu_{t}$, respectively, and the corresponding reliability is $\mathrm{R}_{\mathrm{t}}^{[8-9]}$, then we have the relation:

$\mathrm{R}_{\mathrm{t}}=\mu_{\mathrm{t}} /\left(\lambda_{\mathrm{t}}+\mu_{\mathrm{t}}\right) \quad(\mathrm{t}=1,2, \ldots, \mathrm{n})$

\section{Machinery subsystem reliability}

Gas monitoring system does it work by using detection technology and equipment for continuous monitoring of gas concentration, the harmful gas, wind speed,air volume and the 
equipment running status at the workplace of coal mine underground,forecasting the accident,executing agency action if necessary, improve safety situations and climate conditions in coal mine so that to avoid gas accident. Reliability refers to there will be no changes of physical-mechanical properties and storage conditions which lead to outburst within the scope of the coal seams at the mining working face. Mainly refers to the soft layer in the coal seam, gas pressure gradient, the gas sealing performance in the roof and floor,seam dip angle, fault zone, the distribution of gas, coal seam thickness and mechanical properties should be in security ranges. Coal seam energetic failure rate refers to the number of changes which may lead to coal and gas outburst in unit of time, and it is the reciprocal of the mean time between failures. The coal recovery rate refers to the number of normal state after changes in coal seam in unit of time, it is the reciprocal of the mean time to repair. When we study the failure rate and repair rate in the system,it is easy to find that there is a direct relationship between them and the coal seam storage conditions.

Take the mine excavation footage of each class as a unit of count, and failures within a certain scope of coal mining working face in the geological structure can be seen as geological structure failure rate. The roadway length that influenced by geological structure divided by the excavation footage of each class,we will get the number of geological structure changes (For instance, the farthest distance between outburst and geologic fault is $16 \mathrm{~m}^{[10]}$ at the mine of NO.10 in Pingdingshan coal mines). Therefore, the geological structure failure rate refers to the number of changes which may lead to coal and gas outburst by geological structure of coal seam in unit time.Similarly, we can get the failure rate and repair of soft layer, gas pressure gradient, the gas sealing performance in the roof and floor,coal seam dip angle,fault fracture zone,gas distribution,coal seam thickness ratio in coal bed.

The reliability of the supporting means that the mining face supporting form and quality are in accordance with the relevant provisions of the"coal mine safety regulations", and there should be no roof falling accident.

The reliability of operation means that there should be no blasting and other operations which may lead to coal and gas outburst during the production, operators should not use hand picks or pneumatic pick tools that may induce coal and gas outbursts.

\section{Subsystem reliability of the environment}

The reliability of the operating environment means that the air temperature,humidity, wind speed, dust and harmful gas concentration etc. in airflow and the vibration,noise,lighting and space at the working face are in line with the "China Coal Mine Safety Regulations". The mine micro-climate mainly refers to the mine air temperature, humidity and wind speed. The air pollution is mainly from coal dust,toxic and harmful gases. Toxic and harmful gases are mostly carbon monoxide, carbon dioxide,sulfur dioxide and hydrogen sulfide, etc..They are generated from blasting smoke, mineral oxidation, fire and the exhausted gas by engine."China Coal Mine Safety Regulations" provides the maximum allowable concentration of harmful gases. The changes of variables in the working environment does not lead to coal and gas outburst directly, but they may affect the reliability of the operators and equipment.

\section{Subsystem reliability of man}

Mining workers, technical personnel, management personnel, gas monitoring personnel complete their respective responsibilities under certain conditions and without using operations that may cause coal and gas outburst, technology personnel forecasting and finding soft layers, watching seams like large gas pressure gradient, gas sealed well in the roof and floor of the 
coal seams, dip angle changes,places where the geological structure and gas distribution are not uniform, places where great variation in thickness, mining engineering layout is not reasonable etc.. Management staff should find the source of danger timely at the working face which likely to lead to the coal and gas outburst, so that to prevent the occurrence of outburst accident.The basic reliability of operators ${ }^{[5]}$ can be expressed as follows:

$\mathrm{R}=\mathrm{R}_{1} \mathrm{R}_{2} \mathrm{R}_{3}=0.999 \times 0.995 \times 0.999=0.993$

In the formula, $\mathrm{R}_{1}$ is the input reliability (considering failure of the sensing signal), we take value $0.999 . R_{2}$ is judging reliability (considered judgment mistakes),

we take 0.995 . $R_{3}$ is the output reliability(considering the output information, the execution is fault by the motion organ ), and we take the value 0.999 . Due to the operators own factors and specific working environment underground,the reliability ofworkers will be affected by the micro-climate,lighting,noise, dust and other factors. According to the related literature ${ }^{[6,7]}$,the reliability of works under the specific environments in the coal mine can be drawn.

\section{Reliability calculation}

According to the logical relations of the system units and the trait of the system operation, we get the function of mine outburst prevention system logical diagram as shown in Fig. 2:

(1) System reliability of series components can be calculated as follows:

$$
R=\prod_{i=1}^{n} R_{i}
$$

Where $\mathrm{R}_{\mathrm{i}}$-The reliability of each component,

$\mathrm{n}-\mathrm{The}$ number of elements,

$\Pi-$ Continuous multiplication

(2)System reliability of parallel components can be calculated as follows:

$R=1-\prod_{i=1}^{n}\left(1-R_{i}\right)$ 西 


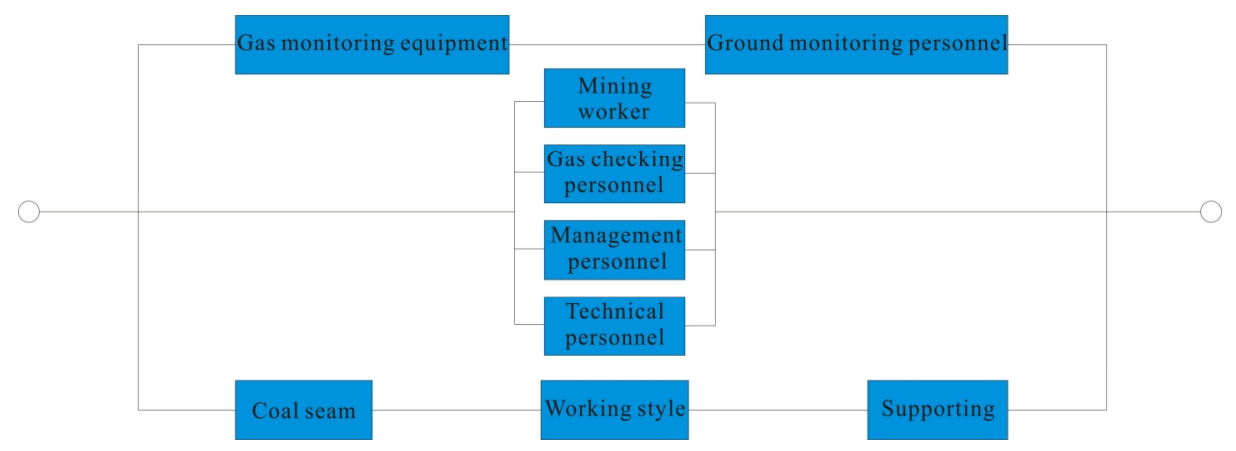

Fig.2 The function of mine outburst prevention system logical diagram

According to formulas(1),(2)and diagram 2, the reliability of the outburst prevention system can be expressed as follows:

$$
\begin{aligned}
& \mathrm{R}=1-\left(1-\mathrm{R}_{1}\right)\left(1-\mathrm{R}_{2}\right)\left(1-\mathrm{R}_{3}\right) \\
& \mathrm{R}_{1}=\mathrm{R}_{\text {coal seam }} \times \mathrm{R}_{\text {working }} \times \mathrm{R}_{\text {supporting }}
\end{aligned}
$$

$\mathrm{R}_{\text {coal seam }}=\mathrm{R}_{\text {pressure gradient }} \times \mathrm{R}_{\text {pressure distribution }} \times \mathrm{R}_{\text {coalbed thickness }} \times \mathrm{R}_{\text {dip angle }} \times \mathrm{R}_{\text {roof }} \times \mathrm{R}_{\text {geological structure }} \times \mathrm{R}_{\text {soft layer }}$ (8)

$\mathrm{R}_{2}=\mathrm{R}_{\text {monitoring equipment }} \times \mathrm{R}_{\text {ground monitoring personnel }}$

$$
\mathrm{R}_{3}=1-\left(1-\mathrm{R}_{\text {mining }}\right)\left(1-\mathrm{R}_{\text {gas checking }}\right)\left(1-\mathrm{R}_{\text {governing }}\right)\left(1-\mathrm{R}_{\text {technology }}\right)
$$

\section{Instance analysis}

The mine in this study locates at pear Bay mine,the eastern area of Zhadu sector,Xinwansan mines,Anping town,the city of Lianyuan,Hunan Province. Where the coal seam 5 has the advantages of simple structure, stable, and the average thickness of $1.5 \mathrm{~m}$, and there is a dark grey to black granular structure of coal powder. The footwall coal seam has a monoclinal structure, and the inclination angle is between $17^{0} \sim 25^{\circ}$,secondary structure is mainly with small faults and structural type is medium. The relative gas emission rate is $43.7 \mathrm{~m}^{3} / \mathrm{t}$, and it belongs to the coal and gas outburst mine.The mine takes the method of inclined shaft development,two levels stoping. The NO.5 coal seam which locates at $+25 \mathrm{~m} \sim+50 \mathrm{~m}$ section is now in stoping. This section is divided into North and South wings and arranged along the direction of $130 \mathrm{~m}$, within the scope, there are 2 working face (5151 face, 5152 face)has been arranged,and four tunneling working surfaces(5151 and 5152 advanced machine lanes. The $+25 \mathrm{~m}$ north transport roadway Lane and the $+25 \mathrm{~m}$ south transport roadway Lane). The reliability index of each unit of the outburst prevention system in mining face are shown in Table 1. 


\begin{tabular}{|c|c|c|c|c|c|c|c|c|c|}
\hline No. & System unit & $\begin{array}{l}\text { Total time of fault } \\
\qquad(\mathrm{min})\end{array}$ & $\begin{array}{l}\text { Total time of work } \\
\text { (min) }\end{array}$ & $\begin{array}{c}\text { Fault } \\
\text { (times) }\end{array}$ & $\begin{array}{l}\text { Mean fault time } \\
\text { (time/min) }\end{array}$ & $\begin{array}{l}\text { Mean working time } \\
\text { (time/min) }\end{array}$ & $\begin{array}{l}\text { Fault rate } \\
\text { (time/min) }\end{array}$ & $\begin{array}{r}\text { Repair rate } \\
\text { (time/min) }\end{array}$ & Reliability \\
\hline 1 & $\begin{array}{c}\text { Gas monitoring } \\
\text { Equipment }\end{array}$ & 120000 & 151960 & 50 & 2400 & 3039.2 & 0.000329 & 0.000417 & 0.559 \\
\hline 2 & Working style & 2880 & 151960 & 6 & 480 & 25327 & 0.000039 & 0.002083 & 0.982 \\
\hline 3 & Supporting & 4800 & 151960 & 10 & 480 & 15196 & 0.000066 & 0.002083 & 0.969 \\
\hline 4 & Soft layer & 10000 & 151960 & 6 & 1667 & 25327 & 0.000039 & 0.0006 & 0.939 \\
\hline 5 & Gas pressure gradient & 22000 & 151960 & 9 & 2444 & 16884 & 0.000059 & 0.000409 & 0.874 \\
\hline 6 & Dip angle & 35000 & 151960 & 6 & 5830 & 25327 & 0.000039 & 0.000172 & 0.815 \\
\hline 7 & Roof and floor & 9600 & 151960 & 20 & 480 & 7598 & 0.000122 & 0.00208 & 0.945 \\
\hline 8 & Geological structure & 43200 & 151960 & 40 & 1080 & 3799 & 0.000263 & 0.000926 & 0.779 \\
\hline 9 & Coalbed thickness & 19200 & 151960 & 40 & 480 & 3799 & 0.000263 & 0.00208 & 0.889 \\
\hline 10 & Gas distribution & 40000 & 151960 & 12 & 3333 & 12663 & 0.000078 & 0.0003 & 0.794 \\
\hline
\end{tabular}

The coal mine safety monitoring system has been equipped with the KJ90 type,and it has 11 methane sensors. These sensors are installed at places to monitoring mining working faces and their return air.The measured working environment and influence coefficients ${ }^{[7]}$ of the reliability are shown in Table 2.

Table 2 The working environmental factors and influence coefficients

\begin{tabular}{|c|c|c|c|c|c|c|c|}
\hline Name & $\begin{array}{c}\text { Temperature } \\
\mathbf{t}\left({ }^{\circ} \mathrm{C}\right)\end{array}$ & $\begin{array}{c}\text { Air speed } \\
\mathbf{v}(\mathbf{m} / \mathbf{s})\end{array}$ & $\begin{array}{c}\text { Coal dust } \\
\text { concentration } \\
\mathbf{q}\left(\mathbf{m g} / \mathbf{m}^{3}\right)\end{array}$ & $\begin{array}{c}\text { Lighting } \\
\mathbf{L x}\end{array}$ & $\begin{array}{c}\text { Noise } \\
\mathbf{d B}\end{array}$ & $\begin{array}{c}\text { Working } \\
\text { space }\end{array}$ & $\begin{array}{c}\text { Vibration } \\
\left(\mathbf{m} / \mathbf{s}^{2}\right)\end{array}$ \\
\hline $\begin{array}{c}\text { Working face } \\
\text { value }\end{array}$ & 26 & 1.5 & 15 & 30 & 90 & narrow \\
\hline $\begin{array}{c}\text { Reliability } \\
\text { influence } \\
\text { factor }\end{array}$ & $\mathrm{k}_{1}=0.983$ & $\mathrm{k}_{2}=1$ & $\mathrm{k}_{3}=0.990$ & $\mathrm{k}_{4}=0.992$ & $\mathrm{k}_{5}=0.987$ & $\mathrm{k}_{6}=0.991$ & $\mathrm{k}_{7}=0.993$ \\
\hline
\end{tabular}

Note: the influence of work environment on gas monitoring equipment can be measured by the repair rate and failure rate.

\section{Reliability of the outburst prevention system at mining working face}

According to Table 2 and former equations,we get,

Table 3 Reliability of the relevant items

\begin{tabular}{|c|c|c|c|}
\hline Item name & Expression & Equation & Value \\
\hline Environmental influence coefficient & $\mathrm{K}$ & $\mathrm{k}_{1} \mathrm{k}_{2} \mathrm{k}_{3} \mathrm{k}_{4} \mathrm{k}_{5} \mathrm{k}_{6} \mathrm{k}_{7}$ & 0.938 \\
\hline Gas checking personnel reliability & $\mathrm{R}_{\text {gas checking }}$ & $\mathrm{KR}$ & 0.931 \\
\hline Management reliability & $\mathrm{R}_{\text {governing }}$ & $\mathrm{KR}$ & 0.931 \\
\hline Technical personnel reliability & $\mathrm{R}_{\text {technology }}$ & $\mathrm{KR}$ & 0.931 \\
\hline
\end{tabular}




\begin{tabular}{|c|c|c|c|}
\hline Ground monitoring personnel reliability & $\begin{array}{c}\mathrm{R}_{\text {ground monitoring }} \\
\text { personnel }\end{array}$ & $\mathrm{R}$ & 0.993 \\
\hline Mining workers reliability & $\mathrm{R}_{\text {mining worker }}$ & $\mathrm{R}$ & 0.993 \\
\hline
\end{tabular}

And based on Table 1,it is easy to get values of equations (6) (10)

Table 4 The reliability of the outburst prevention system

\begin{tabular}{|c|c|c|}
\hline Expression & Equation & Value \\
\hline $\mathrm{R}_{\text {coal seam }}$ & $\begin{array}{c}\mathrm{R}_{\text {pressure gradient }} \times \mathrm{R}_{\text {pressure distribution }} \times \mathrm{R}_{\text {coal thickness }} \times \\
\mathrm{R}_{\text {dip angel }} \times \mathrm{R}_{\text {roof }} \times \mathrm{R}_{\text {geological structure }} \times \mathrm{R}_{\text {soft layer }}\end{array}$ & 0.348 \\
\hline $\mathrm{R}_{1}$ & $\mathrm{R}_{\text {coal seam }} \times \mathrm{R}_{\text {working }} \times \mathrm{R}_{\text {supporting }}$ & 0.331 \\
\hline $\mathrm{R}_{2}$ & $\mathrm{R}_{\text {monitoring equipment }} \times \mathrm{R}_{\text {ground monitoring personnel }}$ & 0.555 \\
\hline $\mathrm{R}_{3}$ & $1-\left(1-\mathrm{R}_{\text {mining }}\right)\left(1-\mathrm{R}_{\text {gas checking }}\right)\left(1-\mathrm{R}_{\text {governing }}\right)\left(1-\mathrm{R}_{\text {technology }}\right)$ & 0.999 \\
\hline $\mathrm{R}$ & $1-\left(1-\mathrm{R}_{1}\right)\left(1-\mathrm{R}_{2}\right)\left(1-\mathrm{R}_{3}\right)$ & 0.9997 \\
\hline
\end{tabular}

\section{Reliability of the outburst prevention system after downsizing staff}

If the we only hire one person in charge of mining,gas checking,technology and management, then the system reliability will be(other conditions can also be calculated by this method):

$\mathrm{R}_{3}=1-\left(1-\mathrm{R}_{\text {mining }}\right)\left(1-\mathrm{R}_{\text {governing }}\right)=1-0.069^{2}=0.995$

$\mathrm{R}=1-\left(1-\mathrm{R}_{1}\right)\left(1-\mathrm{R}_{2}\right)\left(1-\mathrm{R}_{3}\right)=0.998$

\section{Reliability of the outburst prevention system on middle and night shift}

During the middle and night shift time, there will be no technical personnel and management personnel in the working place, then the system reliability will be:

$\mathrm{R}_{3}=1-\left(1-\mathrm{R}_{\text {mining }}\right)\left(1-\mathrm{R}_{\text {gas checking }}\right)=1-0.069^{2}=0.995$

$\mathrm{R}=1-\left(1-\mathrm{R}_{1}\right)\left(1-\mathrm{R}_{2}\right)\left(1-\mathrm{R}_{3}\right)=0.998$

\section{Conclusions}

(1) Gas monitoring equipment reliability $\mathrm{R}=0.559$, which gets the minimum value.That is mainly because the operation environment is bad underground, and all kinds of poisonous and harmful gas, vibration, dust, moisture,ect. have great effects on the monitoring sensor, converter,cable and signal transmission equipment ${ }^{[11]}$.

(2) The failure rate and repair rate of the soft layer in the coal seam, gas pressure gradient,gas sealing performance in the roof and floor,seam dip angle, fault zone, distribution of gas,coal seam thickness and mechanical properties have direct relationship to the coal seam storage conditions, and their reliability, $\mathrm{R}=0.348$, is determined by coal layers.

(3) There are four parallel units in the man subsystem, so there is a higher reliability in the man subsystem,so it can avoid the failure of gas monitoring equipment effectively. However, because 
during the middle and night shift time, there will be no technical personnel and management personnel in the working place,the parallel system unit is reduced to two, which lead to the reduction of the reliability,so, the possibility of the outburst accident will increase ${ }^{[1]}$.

(4) Experience and professional knowledge are very important for technical staff like mining,measurement,geological workers. With the help of exploration equipment, they can predict changes of the coal seam storage condition. Operation reliability of the underground workers at the mining working face is significantly reduced due to effects of micro-climate, lighting, noise, dust and other factors.In order to the need to improve the reliability of outburst prevention, we should improve the working environment underground.

\section{References}

[1] Wang Jie-fan, Li Wen-jun.Chinese coal mine accidents and experts comment anthology(volume one)[M].Beijing:China Coal Industry Publishing House,2002:1295-1431.

[2] Zhou Shi-ning,Lin Bo-quan. The theory of gas flow and storage in coal seams.[M].Beijing:China Coal Industry Publishing House,1999:12-46.

[3] Cheng Wuyi,Zhang Xuming,Wu Fuchang.Coal and gas outburst region prediction theory and technology. [M].Beijing:China Coal Industry Publishing House,2005:82-112.

[4] Feng Shu-hu .The Qualitative and Quantitative Analysis of the Human Reliability in Coal-mine Production[J]. Fuxin:Journal of Liaoning Technical University(Natural Science),2000, 19(4):445-448.

[5] Zhang Jing-lin, Cui Guo-zhang.Safety system engineering[M].Beijing:China Coal Industry Publishing House, 2005:52-102.

[6] Ouyang Wen-zhao, Liao Ke-bing.Safety Ergonomics[M].Beijing:China Coal Industry Publishing House, 2002: 60-91.

[7] Zhu Chuan-qu, Wang Wei-jun.Reliability of the Man-Machine-Environment System of Fully Mechanized Face [J].Beijing:Systems Engineering-Theory \&Practice, 1999,19(4):109-114.

[8]Song Bao-wei.Design and analysis for the reliability of the system[M]. Xi'an: North western Polytechnical University Press Co.Ltd.,2000:18-65.

[9] Guo Yong-ji.The theory of reliability engineering[M].Beijing:Tsinghua University Press,2002:11-70.

[10] Xu Xuefeng.Effect study of geological structure to the coal and gas outburst[D].Fuxin:Liaoning Technical University,2003:12-55.

[11] Sun Jian-hua,Shao Zhi-mei.Reliability analysis of gas monitoring system.[J]. Beijing:Coal Mine Machinery, 2004:51-52. 